\title{
Numerical investigation of solar energy storage by a salt gradient solar pond in several Moroccan cities
}

\author{
Abdessamad Nait Brahim ${ }^{1}$, Yassmine Rghif ${ }^{*}$ and Fatima Bahraoui ${ }^{1}$ \\ ${ }^{1}$ Team of Heat Transfer and Energetic (UAE/U10FST), Faculty of Sciences and Techniques of Tangier, Abdelmalek Essaâdi \\ University, Morocco
}

\begin{abstract}
Numerical investigation of solar energy storage by a Salt Gradient Solar Pond (SGSP) in several Moroccan cities (Marrakesh, Ouarzazate, Tangier and Ifrane) is presented in this paper. For this purpose, the SGSP considered is assimilated to an open parallelipedic cavity in which the vertical and bottom walls are thermally insulated. The one-dimensional numerical model developed in Python programming language is based on the energy balance of each SGSP zone in which the heat losses via the SGSP free surface are retained. The numerical results obtained from the model developed are satisfactorily compared and validated against those obtained experimentally and numerically from a literature study. According to the results of one year of the SGSP operation, the storage zone temperature and the energy stored in the SGSP located in Ouarzazate city are the highest and reach maximum values in July (about $128^{\circ} \mathrm{C}$ and $146 \mathrm{MJ}$ respectively). Moreover, comparisons between different mass flow rates $(0.01 \mathrm{Kg} / \mathrm{s}, 0.05 \mathrm{Kg} / \mathrm{s}$ and $0.09 \mathrm{Kg} / \mathrm{s})$ of heat exchanger placed in the storage zone show that the optimal one is $0.09 \mathrm{Kg} / \mathrm{s}$ as it ensures the maximum energy extraction.
\end{abstract}

\section{Introduction}

Solar energy is a renewable, clean and reliable source of energy. However, the major disadvantage of this energy source is its intermittency. Thus, there is a necessity to store the energy produced by using an energy storage system such as a Salt Gradient Solar Pond (SGSP). This last one is an artificial saltwater pond offering an alternative way to capture and store solar energy as sensible heat. The latter is useful for various applications [1] like power generation [2], desalination [3] and lower temperature industrial processes [1]. Usually, a SGSP consists of three horizontal saltwater zones: Upper Convective Zone (UCZ), Non-Convective Zone (NCZ) and Lower Convective Zone (LCZ) [4]. The UCZ of lower level of salt concentration composes the upper part of the pond. This zone captures the solar radiation and protects the SGSP from external vagaries. The NCZ of gradient sat concentration is located in the SGSP middle (between UCZ and LCZ). This zone is considered as thermal insulator by minimizing heat transfer between the UCZ and LCZ. The LCZ of high level of salt concentration is situated at the SGSP bottom. In this zone, thermal energy is stored as sensible heat and can be extracted via a heat exchanger that is conventionally placed in the LCZ [5],[6]. Nevertheless, El Mansouri et al. [7] demonstrated that extracting heat using horizontal and vertical tubes in LCZ and NCZ, respectively, provides better energy and exergy efficiency.

In 2017, the El Mansouri et al. study [8] was the first SGSP study conducted by Moroccan researches. It involves the development of a 2D numerical model to quantitatively and qualitatively investigate the thermal characteristics of a small SGSP operating in a semi-arid Moroccan climate (Marrakech). The numerical model, based on the hybrid Finite-Volume Lattice-Boltzmann method, was validated numerically and experimentally by comparisons with literature works. On the basis of five days of the SGSP operation, the LCZ temperature increases from $25^{\circ} \mathrm{C}$ to $49.4^{\circ} \mathrm{C}$ and the stored energy exceeds $40 \mathrm{MJ}$. In addition, the SGSP daily efficiency varies from $25.6 \%$ to $36.5 \%$. Based on these results, the authors confirm the feasibility of SGSP in the semi-arid climate of North Africa [8]. On the other hand, the same authors demonstrated, in another numerical study [9], that the storage zone temperature increases every day by around $5{ }^{\circ} \mathrm{C}$ [9]. Furthermore, the energy stored in the $\mathrm{NCZ}$ and LCZ reaches, at the end of the simulation period (5 days), $5.9 \mathrm{kWh}$ and $11.3 \mathrm{kWh}$ respectively. Following the El Mansouri et al. studies [7]-[9], Rghif et al. [4], [10]-[12] focused on Soret effect (the mass transfer caused by the temperature gradient) and Dufour effect (the heat transfer caused by the salt concentration gradient) developed in SGSPs under meteorological conditions of Tangier city in Morocco. To this end, a 2D numerical model was developed in Fortran 95 basing on Navier-Stokes, thermal energy and diffusion equations. Results show that Soret effect has not a significant influence on heat and mass transfer in the SGSP compared to Dufour effect. This last one influences the temperature distribution inside the SGSP in which the LCZ dimensionless temperature decreases from 0.894 to

\footnotetext{
${ }^{*}$ Corresponding author : rghifyassmine@gmail.com
} 
0.764 by increasing Dufour coefficient from 0 to 0.8 . Moreover, the amount of heat stored reduces by about $5.56 \%$ and the heat loss increases by about $8.53 \%$ [11]. Authors concluded that Dufour effect perturbs the SGSP operating mechanism through the increase of heat and mass transfer from the lower convective zone to the upper convective zone [11]. In a further development, Rghif et al. [13] proposed to combine sensible heat storage and latent heat storage by integrating the Paraffin Wax as a Phase Change Material (PCM) into a SGSP. Results reveal that the amount of heat loss through the free surface is higher and the SGSP temperature and thermal efficiency with the PCM are lower than the SGSP without the PCM. Nevertheless, Dufour effect is mitigated in the SGSP with the PCM. Thus, it is recommended to integrate the PCM into the SGSP if the value of the Dufour coefficient is high and uniform low temperature heat is desired [13].

It appears from the literature that the SGSP studies are very limited in Morocco despite a high annual sunshine rate (3000 hours [14]). It is therefore necessary to investigate the solar energy storage by a SGSP in several Moroccan cities, which is the objective of this study. This investigation is based essentially on the energy balance of each SGSP zone.

\section{Mathematical formulation}

\subsection{Physical model}

The SGSP considered in this work is assimilated to an open parallelipedic cavity $(\mathrm{L}=0.8 \mathrm{~m} \times 1=0.8 \mathrm{~m} \times \mathrm{H}=$ $1 \mathrm{~m})$ with impermeable and thermally insulated bottom and vertical walls (Fig. 1). It is filled with a solution of Sodium Chloride ( $\mathrm{NaCl}$ solution) and subdivided into three zones: $\mathrm{LCZ}$ with a thickness $\mathrm{h}_{1}=0.4 \mathrm{~m}$ and a saline concentration $\mathrm{C}_{1}=140 \mathrm{~kg} / \mathrm{m}^{3}$, NCZ with a thickness $\mathrm{h}_{2}$ $=0.4 \mathrm{~m}$ and a saline concentration $\mathrm{C}_{2}$ varies linearly with depth and UCZ with a thickness $\mathrm{h}_{3}=0.2 \mathrm{~m}$ and a saline concentration $\mathrm{C}_{3}=0 \mathrm{~kg} / \mathrm{m}^{3}$.

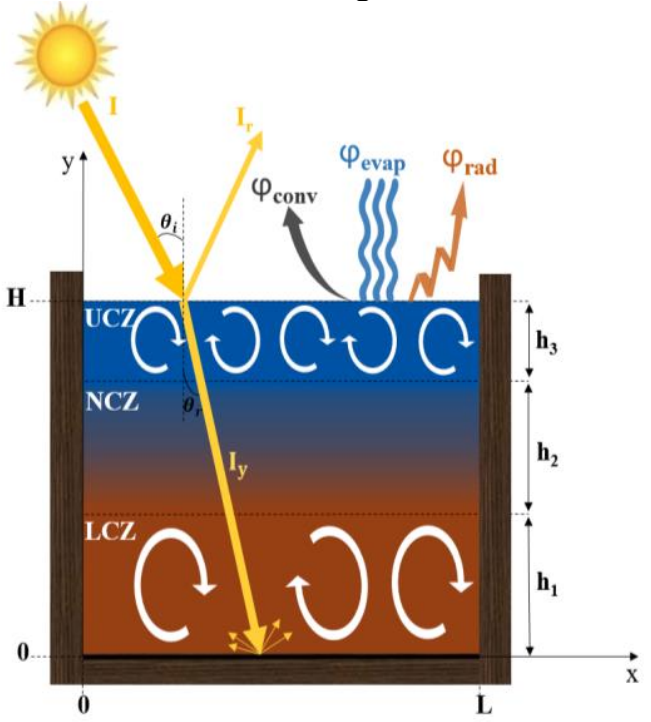

Fig. 1. Schematic view of the salt gradient solar pond considered [10].

\subsection{Solar irradiation absorption model}

As the solar radiation reaches the SGSP surface (I), a proportion is immediately reflected towards the environment $\left(I_{r}\right)$. The rest of the solar radiation $\left(I_{0}\right)$ is penetrated into the saline water. This amount is obtained from equation (1) [15].

$$
I_{0}=(1-R) I
$$

With $R$ is the reflection coefficient. This last one is calculated according to equation (2) for the air-water interface [15].

$$
R=\frac{1}{2}\left[\frac{\sin ^{2}\left(\theta_{i}-\theta_{r}\right)}{\sin ^{2}\left(\theta_{i}+\theta_{r}\right)}+\frac{\tan ^{2}\left(\theta_{i}-\theta_{r}\right)}{\tan ^{2}\left(\theta_{i}+\theta_{r}\right)}\right]
$$

$\theta_{i}$ and $\theta_{r}$ are respectively the incident and refraction angles (Fig. 1). They are related by the refraction index $(n=1.33$ for water [15]) as follow [15]:

$$
\begin{gathered}
n=\frac{\sin \theta_{i}}{\sin \theta_{r}} \\
\cos \theta_{i}=\cos \delta \cos \varphi \cos \omega+\sin \delta \sin \varphi
\end{gathered}
$$

Where $\varphi$ the angle of latitude, $\delta$ is the angle of declination and $\omega$ the hour angle. $\delta$ and $\omega$ are calculated by equations (5) et (6), respectively [15].

$$
\begin{gathered}
\delta=23.45 \sin \left[\frac{2 \pi}{365}(284+N)\right] \\
\omega=\frac{2 \pi(h-12)}{24} \\
\omega=\frac{2 \pi(h-12)}{24}
\end{gathered}
$$

Where $N$ is the number of day in year and $h$ is the local time hour.

The amount of the solar radiation $\left(I_{y}\right)$ reaching a depth $y$ in the saline water (Fig. 1) is determined as follow [15]:

$$
I_{y}(y, t)=I_{0} \theta^{\prime} h(y)
$$

Where $\theta^{\prime}$ represents the effects of solar irradiation reduction in the SGSP such as the saline water turbidity $\left(\theta^{\prime}=0.85[15]\right) . h(y)$ is the rate of solar radiation decaying through the SGSP depth and is calculated by equation (8) [15]:

$$
h(y)=0.36-0.08 \ln \left(\frac{y}{\cos \left(\theta_{r}\right)}\right)
$$

\subsection{Transfer equations}

In this work, the following assumptions are adopted: - The natural convection in UCZ and LCZ is neglected; 
- The internal walls of the pond are blackened;

- The solar radiation reaching the LCZ is totally absorbed in this zone;

- The free surface of the pond is submitted to heat losses by convection $\left(\varphi_{\text {conv }}\right)$, evaporation $\left(\varphi_{\text {evap }}\right)$ and radiation $\left(\varphi_{r a d}\right)$;

- The thermo-physical properties of saltwater (thermal conductivity $\lambda$, specific heat $C_{p}$ and density $\rho$ ) are constant;

- The initial temperature of the saltwater composed the three SGSP zones is the same and equal to $18^{\circ} \mathrm{C}$.

Based on the above assumptions and the energy balance of each SGSP zone, the mathematical model can be written as follows:

- The UCZ temperature $\left(T_{U C Z}\right)$ is assumed uniform and calculated by equation (9).

$$
\begin{aligned}
\rho C_{P} S h_{3} \frac{\partial T_{U C Z}}{\partial t}= & \varphi_{\text {solar }, U C Z}+\varphi_{N C Z / U C Z}-\varphi_{\text {rad }}- \\
& \varphi_{\text {evap }}-\varphi_{c o n v}
\end{aligned}
$$

Where $S$ is the surface area of the SGSP $(\mathrm{S}=\mathrm{L} \times 1=$ $\left.0.64 \mathrm{~m}^{2}\right), \varphi_{\text {solar, } U C Z}$ is the amount of solar radiation absorbed by UCZ and $\varphi_{N C Z / U C Z}$ is the amount of heat transfers by conduction between UCZ and NCZ.

In order to calculate $\varphi_{\text {solar, } U C Z}, \varphi_{N C Z / U C Z}, \varphi_{\text {rad }}, \varphi_{\text {conv }}$ and $\varphi_{\text {evap }}$, equations (10), (11), (12), (14) and (16) are used respectively [11], [15].

$$
\begin{gathered}
\varphi_{\text {solar }, U C Z}=S I_{0}\left(1-h\left(h_{3}\right)\right) \\
\varphi_{N C Z / U C Z}=\lambda S \frac{T_{N C Z}-T_{U C Z}}{\Delta y} \\
\varphi_{\text {rad }}=\varepsilon \sigma S\left[T_{U C Z}{ }^{4}-T_{S k y}{ }^{4}\right] \\
T_{S k y}=0.0552\left(T_{a}\right)^{1,5} \\
\varphi_{\text {conv }}=h_{c} S\left(T_{U C Z}-T_{a}\right) \\
h_{c}=5.7+3.8 U \\
\varphi_{\text {evap }}=\left(\varphi_{\text {free }}^{2}+\varphi_{\text {forced }}^{2}\right)^{1 / 2}
\end{gathered}
$$

With $\varepsilon$ is the water emissivity $(\varepsilon=0.83[15]), \sigma$ is the Stefan-Boltzmann constant $\left(5.6710^{-8} \mathrm{~W} / \mathrm{m}^{2} . \mathrm{K}^{4}\right), T_{S k y}$ is the sky temperature [16], $T_{a}$ is the ambient air temperature, $h_{c}$ is the convection heat transfer coefficient [15], $U$ is the wind speed.

The evaporative heat loss is given, as is expressed in equation (16), as a function of the free $\left(\varphi_{\text {free }}\right)$ and forced $\left(\varphi_{\text {forced }}\right)$ convection. They are calculated as follows [11]:

$$
\begin{aligned}
& \left\{\varphi_{\text {free }}=2.7 \times 10^{-2}\left(T_{U C Z, v}-T_{a, v}\right)^{1 / 2}\left(P_{w}-P_{a}\right) \text { if } T_{U C Z, v} \geq T_{a, v}\right. \\
& \left\{\begin{array}{l}
\varphi_{\text {free }}=2.7 \times 1 \varphi_{\text {free }}=0 \quad \text { if } T_{U C Z, v} \leq T_{a, v}
\end{array}\right. \\
& \varphi_{\text {forced }}=3.1 \times 10^{-2} U\left(P_{w}-P_{a}\right)
\end{aligned}
$$

$P_{a}, P_{w}, T_{w, v}$ and $T_{a, v}$ are respectively the water vapor pressure over the SGSP, the saturated vapor pressure, the virtual water surface temperature and the virtual ambient air temperature. These pressures and temperatures are calculated by equations (19), (20), (21) and (22) respectively [11].

$$
\begin{gathered}
P_{a}=2.1718 \times 10^{10} R_{h} \exp \left(\frac{-4157}{T_{a}-33.91}\right) \\
P_{w}=2.1718 \times 10^{10} \exp \left(\frac{-4157}{T_{U C Z}-33.91}\right) \\
T_{U C Z, v}=\frac{T_{U C Z}}{1-0.378 \frac{P_{w}}{P_{a t m}}} \\
T_{a, v}=\frac{T_{a}}{1-0.378 \frac{P_{a}}{P_{a t m}}}
\end{gathered}
$$

Where $R_{h}$ of equation (19) is the relative humidity.

- The NCZ is subdivided into five sub-zones of similar thickness $(\Delta y=0.08 \mathrm{~m})$ in which the temperature of each sub-zone $\left(T_{N C Z i}\right)$ is considered homogenous. The energy balance of the NCZ can be expressed by equation (23).

$$
\begin{gathered}
\rho C_{P} S \Delta y \frac{\partial T_{N C Z i}}{\partial t}=\lambda \frac{\partial^{2} T_{N C Z i}}{\partial y^{2}}+\left(\varphi_{\text {solar }, N C Z i}+\right. \\
\left.\varphi_{N C Z i+1 / i}-\varphi_{N C Z i / i-1}\right)
\end{gathered}
$$

Where $\varphi_{\text {solar,NCZi }}$ is the amount of solar radiation absorbed by the sub-zone i, $\varphi_{N C Z i+1 / i}$ is the amount of heat transfer by conduction between the sub-zone (i) and the sub-zone above (i+1) and $\varphi_{N C Z i / i-1}$ is the amount of heat transfer by conduction between the sub-zone (i) and the sub-zone below (i-1). They are calculated basing on equations (24), (25) and (26), respectively.

$$
\begin{gathered}
\varphi_{\text {solar }, N C Z i}=S I_{0}\left(h\left(h_{3}+i \Delta y\right)-h\left(h_{3}+(i-1) \Delta y\right)\right) \\
\varphi_{N C Z_{i / i-1}}=\lambda S \frac{T_{i}-T_{i-1}}{\Delta y} \\
\varphi_{N C Z_{i+1 / i}}=\lambda S \frac{T_{i+1}-T_{i}}{\Delta y}
\end{gathered}
$$

- The LCZ temperature $\left(T_{L C Z}\right)$ is assumed uniform and calculated by equation (27).

$$
\rho C_{P} S h_{1} \frac{\partial T_{L C Z}}{\partial t}=\varphi_{\text {solar }, L C Z}-\varphi_{L C Z / N C Z}
$$

Where $\varphi_{\text {solar, } L C Z}$ is the amount of solar radiation absorbed by LCZ (equation (28))) and $\varphi_{L C Z / N C Z}$ is the amount of heat transfer by conduction between $\mathrm{NCZ}$ and LCZ (equation (29)).

$$
\begin{gathered}
\varphi_{\text {solar }, L C Z}=S I_{0} h\left(h_{3}+h_{2}\right) \\
\varphi_{L C Z / N C Z}=\lambda S \frac{T_{L C Z}-T_{N C Z}}{\Delta y}
\end{gathered}
$$

\section{Numerical model validation}

The energy balance equations of each SGSP zone (equations (9), (23) and (24)) are solved using the 
implicit finite difference method written in Python programming language. This numerical model was then adopted for the SGSP El Paso [16] to ensure its validity. Comparisons were conducted for a one-year period (1999) in terms of LCZ and UCZ temperature variations (Fig. 2). As can be seen, a good agreement is noticed between the present model results and the experimental results of the reference study [16]. For the LCZ, the maximum deviation between the experimental and our numerical results does not exceed $10.13{ }^{\circ} \mathrm{C}$, while this deviation reaches $13.9{ }^{\circ} \mathrm{C}$ for the numerical model proposed by the literature study [16]. For the UCZ, the maximum deviation between the experimental and our numerical results is about $3.05{ }^{\circ} \mathrm{C}$ and exceeds $7.7^{\circ} \mathrm{C}$ between numerical and experimental results of the literature [16]. Therefore, the elaborated model will be considered for the rest of this study.

(a)

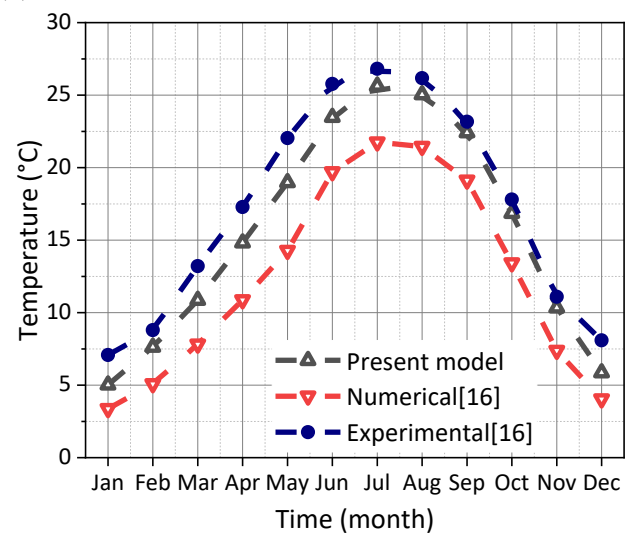

(b)

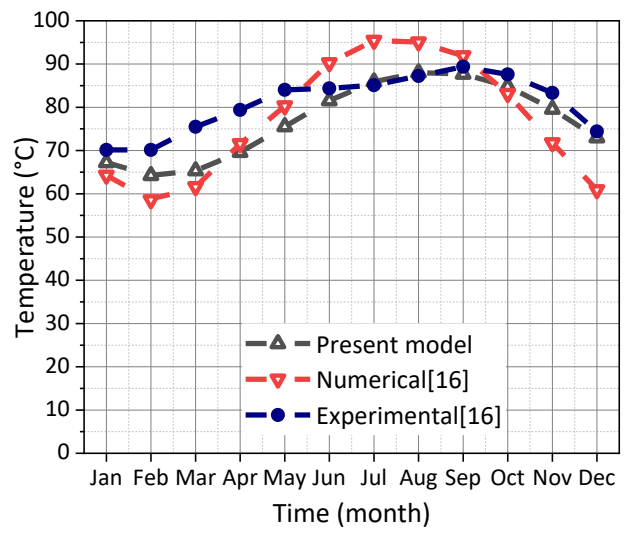

Fig. 2. Variation versus time of the (a) UCZ and (b) LCZ temperatures of the SGSP El Paso.

\section{Results and discussion}

The temperature variation as well as the energy stored in the SGSPs depend on several factors, in particular the weather conditions. For this purpose, four cities (Marrakesh, Ouarzazate, Tangier and Ifrane) characterized by different climates (semi-arid, desertic, mediterranean and humid) were tested. It should be noted that meteorological data illustrated in Fig.3 of these cities are obtained from Meteonorm 7 software. (a)

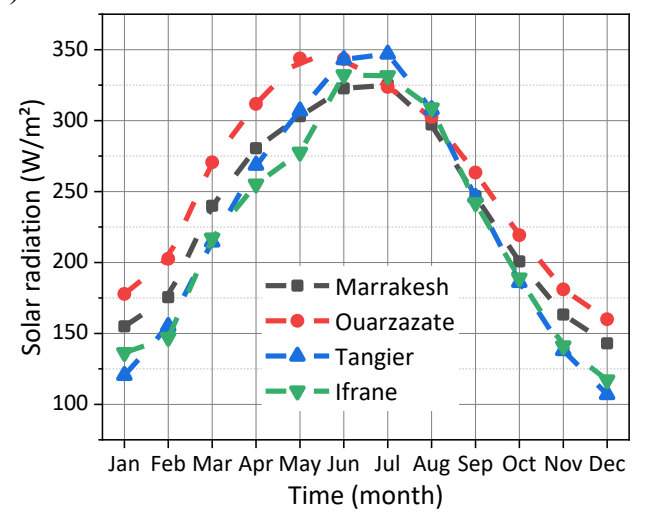

(b)

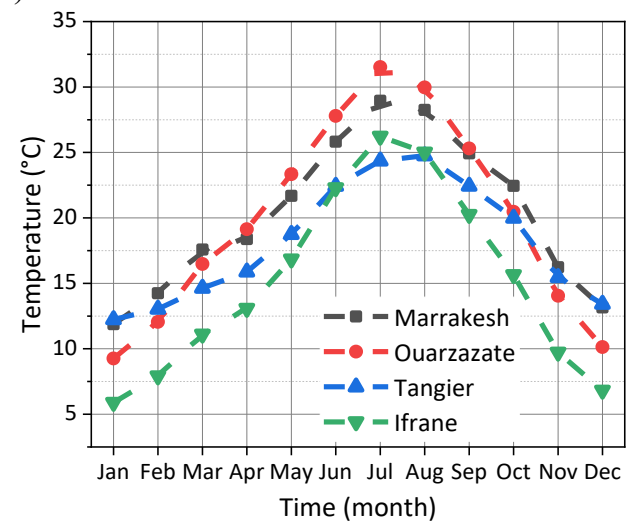

(c)

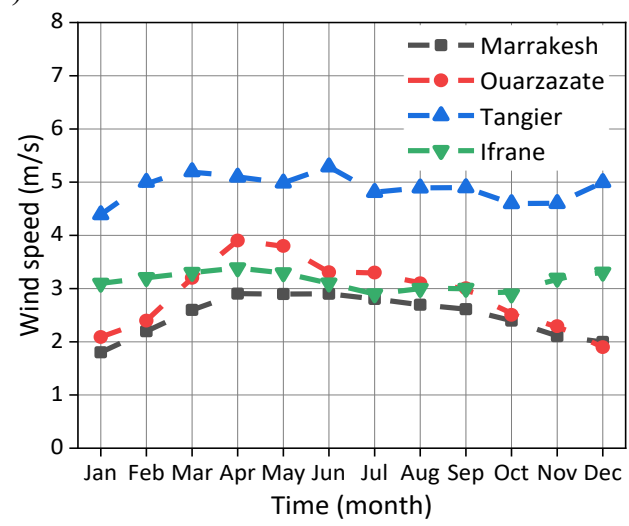

(d)

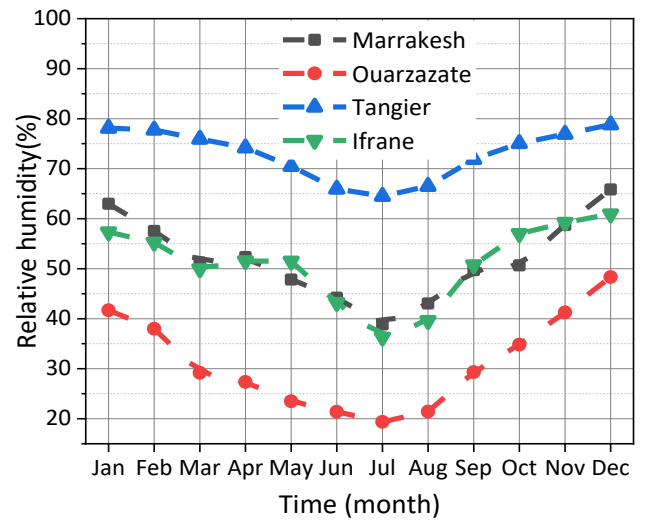

Fig. 3. Variation versus time of the (a) solar radiation, (b) temperature, (c) wind speed and (d) relative humidity in different cities. 


\subsection{Choosing the city}

The temperature variation of the $\mathrm{UCZ}$ and $\mathrm{LCZ}$ for different cities is plotted in Fig.4. As can be seen, the UCZ temperature (Fig. 4-a) is lower than that of the storage zone (Fig. 4-b) regardless of the city considered. Moreover, the UCZ temperature is very close to that of the ambient air (Fig. 4-a). The maximum difference between the ambient air temperature and UCZ temperature is about $1{ }^{\circ} \mathrm{C}$. This is mainly due to the heat transfer between this zone and the ambient air. In addition, the LCZ temperature is higher in Ouarzazate than other cities. For example, it is around $126{ }^{\circ} \mathrm{C}$ in Ouarzazate, $125.5^{\circ} \mathrm{C}$ in Tangier, $121.5^{\circ} \mathrm{C}$ in Marrakesh and $119^{\circ} \mathrm{C}$ in Ifrane at July. This is can be justified by the high solar radiation intensity characterizes this city (Fig. 3-a).

(a)

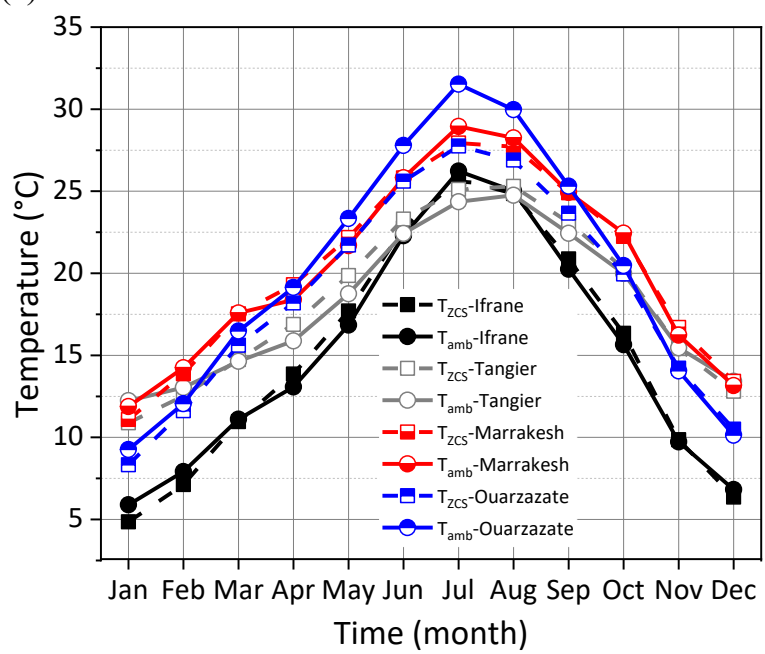

(b)

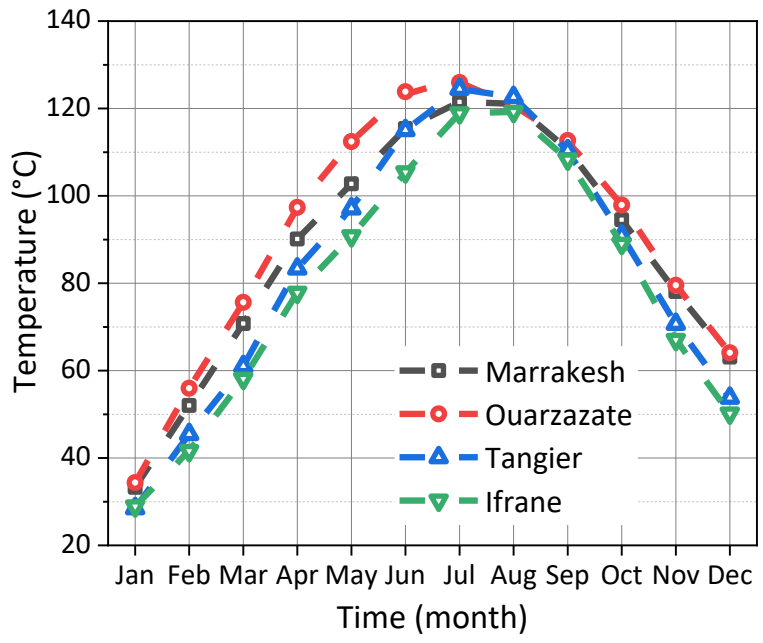

Fig. 4. Monthly variation of the (a) UCZ and (b) LCZ temperatures in different cities.

Fig. 5 illusrates the monthly variation of the stored energy in the four cities. It is clear that whatever the city considered, the energy stored in the $\mathrm{LCZ}$ varies during the year. It is maximal in summer (June, July and August) and minimal in winter (January and December). Moreover, this energy is minimal during most months of the year in Ifrane and maximal in Ouarzazate. As an example, in June, the energy stored is about $145 \mathrm{MJ}$ in Ouarzazate and about $120 \mathrm{MJ}$ in Ifrane.

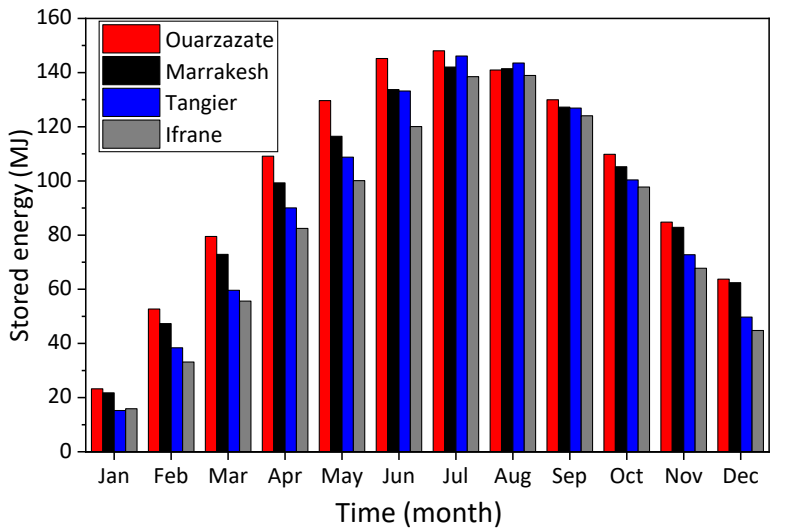

Fig. 5. Energy stored in LCZ for different cities.

From the above, it is obvious that Ouarzazate city is the best Moroccan city compared to other cities for the high temperature and stored energy that ensures. Therefore, the weather conditions of this city are adopted for the rest of this study.

\subsection{Choosing the mass flow of heat exchanger}

In this subsection, a heat exchanger is placed in the LCZ in order to extract the energy stored. Three mass flow rates of the heat transfer fluid (water) are tested: 0.01 $\mathrm{Kg} / \mathrm{s}, 0.05 \mathrm{Kg} / \mathrm{s}$ and $0.09 \mathrm{Kg} / \mathrm{s}$. It should be noted that the heat transfer fluid inlet temperature is assumed to be equal to that of the UCZ. For any appreciable use of the remaining available heat in the SGSP, it is assumed that a minimum temperature difference of $20{ }^{\circ} \mathrm{C}$ must be maintained between the $\mathrm{LCZ}$ and the heat transfer fluid inlet temperatures. We also suppose that the extraction is performed after 60 days of the SGSP operation in which it is activated $24 \mathrm{~h}$ per day.

Fig. 6 depicts the LCZ temperature profile for the different mass flow rates examined. It remains that is the same during the first two months (about $34{ }^{\circ} \mathrm{C}$ in January and $56{ }^{\circ} \mathrm{C}$ in February) because the stored energy is not yet extracted (Fig. 7.b). In March, it drops significantly from $56{ }^{\circ} \mathrm{C}$ to less than $35{ }^{\circ} \mathrm{C}$ due to the heat extraction process (Fig. 7.b). It is also noticed that the stored energy decreases from $53 \mathrm{MJ}$ to $20 \mathrm{MJ}, 15 \mathrm{MJ}$ and $10 \mathrm{MJ}$ for $0.01 \mathrm{Kg} / \mathrm{s}, 0.05 \mathrm{Kg} / \mathrm{s}$ and $0.09 \mathrm{Kg} / \mathrm{s}$ respectively during the first month of extraction (Fig. 7.a). Then, it increases until reaching $35 \mathrm{MJ}, 28 \mathrm{MJ}$ and $24 \mathrm{MJ}$ for $0.01 \mathrm{Kg} / \mathrm{s}, 0.05 \mathrm{Kg} / \mathrm{s}$ and $0.09 \mathrm{Kg} / \mathrm{s}$ respectively during summer (July) and decreases in winter (November, December). This variation of the stored energy can be justified by the variation of the solar radiation which is maximal in summer and minimal in winter (Fig. 3-a). In the same figure (Fig. 6), it is obvious that the temperature reaches higher values if the flow rate is lower. Indeed, for a high flow rate, the extracted energy is greater (Fig. 7-b). Thus, the 
appropriate flow rate for extraction is $0.09 \mathrm{Kg} / \mathrm{s}$ since it ensures the maximum energy extracted.

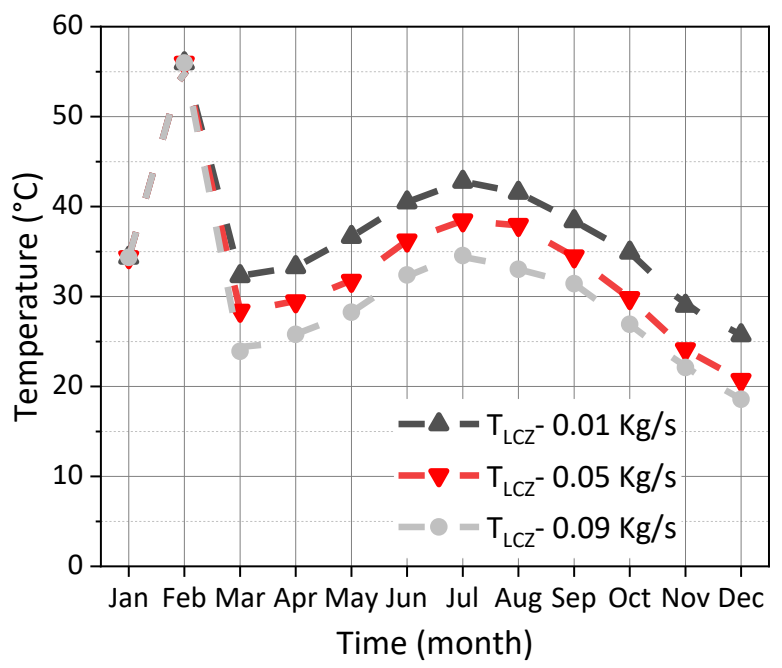

Fig. 6. LCZ temperature with heat extraction.

(a)

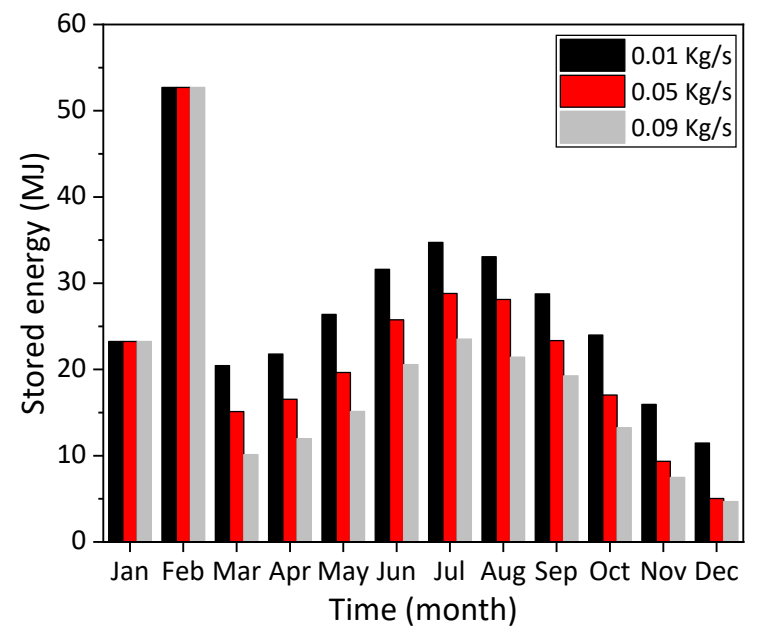

(b)

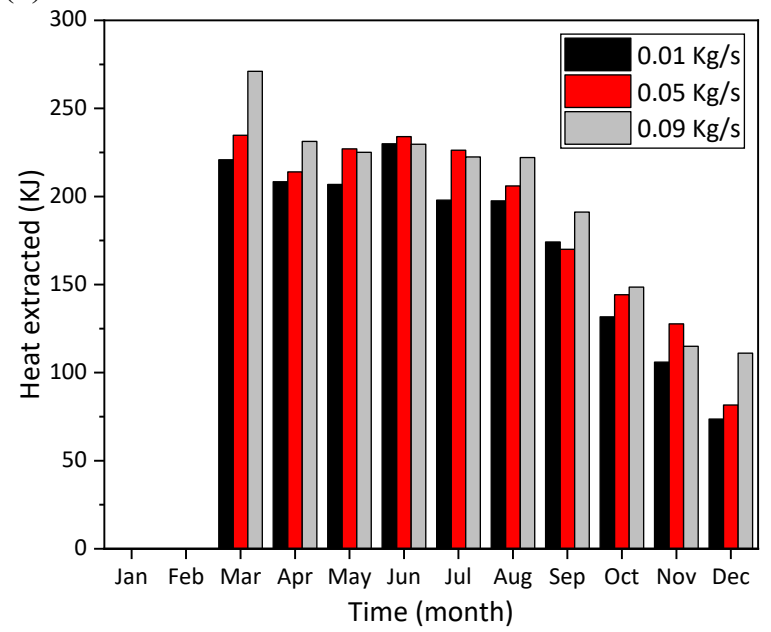

Fig. 7. Monthly variation of (a) stored and (b) extracted energies.

Fig. 8 represents the variation of the extracted energy, temperature of UCZ and LCZ throughout July (the choice of this month is based on the maximum stored energy and temperature obtained for a mass flow rate of the heat transfer fluid equal to $0.09 \mathrm{Kg} / \mathrm{s}$ ). The extracted energy is represented as peaks due to the imposed minimum temperature difference. During the extraction, the stored energy and LCZ temperature decrease until the temperature difference becomes less than $20^{\circ} \mathrm{C}$. In this case, the heat extracted is null because there is no heat extraction (Fig. 8). Moreover, the LCZ temperature increases and then decreases slightly due to the day/night alternation. However, the UCZ temperature is oscillatory due to the heat exchange between the UCZ and the ambient air.

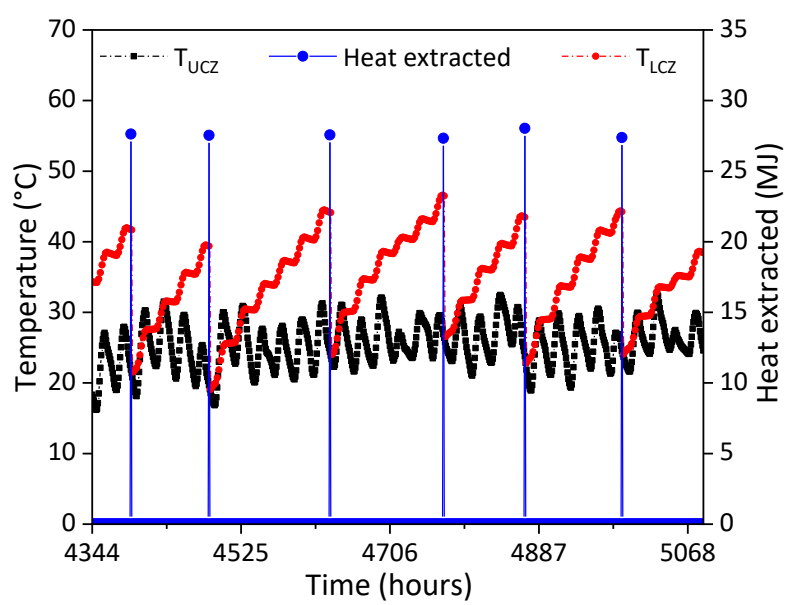

Fig. 8. Variation of extracted energy, temperature of UCZ and LCZ during July.

\section{Conclusion}

In this study, solar energy storage by a salt gradient solar pond in several Moroccan cities (Marrakesh, Ouarzazate, Tangier and Ifrane) is studied numerically. For this purpose, a one-dimensional numerical model was developed in Python programming language basing on the energy balance of each SGSP zone. The absorption of solar radiation and the heat losses via the SGSP free surface are retained. The numerical model was validated with numerical and experimental results of the literature. Results show that the storage zone temperature in Ouarzazate city is the highest and the same for the energy stored. The maximum values obtained are in July and reach about $128{ }^{\circ} \mathrm{C}$ for the temperature and $146 \mathrm{MJ}$ for the stored energy. Moreover, the test of three mass flow rates of the heat transfer fluid (water): $0.01 \mathrm{Kg} / \mathrm{s}, 0.05 \mathrm{Kg} / \mathrm{s}$ and 0.09 $\mathrm{Kg} / \mathrm{s}$ shows that the adequate one is $0.09 \mathrm{Kg} / \mathrm{s}$ since it ensures the maximum energy extracted.

As perspective to this study, we will studying the stability of the SGSP and its impact on energy storage in terms of gradient erosion and gradient growth.

\section{References}

1. K. R. Ranjan and S. C. Kaushik, "Thermodynamic 
and economic feasibility of solar ponds for various thermal applications: A comprehensive review," Renew. Sustain. Energy Rev., vol. 32, pp. 123-139, (2014), doi: 10.1016/j.rser.2014.01.020.

2. R. Singh, S. Tundee, and A. Akbarzadeh, "Electric power generation from solar pond using combined thermosyphon and thermoelectric modules," Sol. Energy, vol. 85, no. 2, pp. 371-378 (2011), doi: 10.1016/j.solener.2010.11.012

3. A. El Mansouri, M. Hasnaoui, A. Amahmid, and S. Hasnaoui, "Feasibility analysis of reverse osmosis desalination driven by a solar pond in Mediterranean and semi-arid climates," Energy Convers. Manag., vol. 221, no. July, p. 113190 (2020), doi: 10.1016/j.enconman.2020.113190.

4. Y. Rghif, B. Zeghmati, and F. Bahraoui, "Soret and Dufour effects on thermal storage and storage efficiency of a salt gradient solar pond," IEEE Xplore, vol. 5 (2020), 10.1109/REDEC49234.2020.9163880.

5. M. Khalilian, H. Pourmokhtar, and A. Roshan, "Effect of heat extraction mode on the overall energy and exergy ef fi ciencies of the solar ponds: A transient study," Energy, vol. 154, pp. 27-37 (2018), doi: 10.1016/j.energy.2018.04.120.

6. A. Date, Y. Yaakob, A. Date, and S. Krishnapillai, "Heat extraction from Non-Convective and Lower Convective Zones of the solar pond: A transient study," Sol. Energy, vol. 97, pp. 517-528 (2013), doi: 10.1016/j.solener.2013.09.013.

7. A. El Mansouri, M. Hasnaoui, A. Amahmid, and Y. Dahani, "Transient theoretical model for the assessment of three heat exchanger designs in a large-scale salt gradient solar pond: Energy and exergy analysis," Energy Convers. Manag., vol. 167, no. April, pp. 45-62 (2018), doi: 10.1016/j.enconman.2018.04.087.

8. A. El Mansouri, M. Hasnaoui, R. Bennacer, and A. Amahmid, "Transient thermal performances of a salt gradient solar pond under semi-arid Moroccan climate using a 2D double-diffusive convection model," Energy Convers. Manag., vol. 151, no. August, pp. 199-208 (2017), doi: 10.1016/j.enconman.2017.08.093.

9. A. El Mansouri, M. Hasnaoui, A. Amahmid, and R. Bennacer, "Transient modeling of a salt gradient solar pond using a hybrid Finite- Volume and Cascaded Lattice-Boltzmann method: Thermal characteristics and stability analysis," Energy Convers. Manag., vol. 158, no. September 2017, pp. 416-429

(2018) 10.1016/j.enconman.2017.12.085.

10. Y. Rghif, B. Zeghmati, and F. Bahraoui, "Modeling of a salt gradient solar pond under Moroccan climate taking into account double-diffusive convection," Mater. Today Proc., vol. 30, pp. 883-888 (2020), doi: 10.1016/j.matpr.2020.04.345.

11. Y. Rghif, B. Zeghmati, and F. Bahraoui, "Soret and Dufour effects on thermosolutal convection developed in a salt gradient solar pond," Int. J. Therm. Sci., vol. 161, no. November 2020, p. 106760 (2021), doi: 10.1016/j.ijthermalsci.2020.106760.

12. Y. Rghif, B. Zeghmati, and F. Bahraoui, "Numerical study of Soret and Dufour coefficients on heat and mass transfer in a salt gradient solar pond," AIP Conf. Proc., vol. 020003, no. April (2021), doi: https://doi.org/10.1063/5.0049389.

13. Y. Rghif, B. Zeghmati, and F. Bahraoui, "Modeling the influences of a phase change material and the Dufour effect on thermal performance of a salt gradient solar pond," Int. J. Therm. Sci., vol. 166, no. March, p. 106979 (2021), doi: 10.1016/j.ijthermalsci.2021.106979.

14. Y. El Mghouchi, A. El Bouardi, and Z. Choulli, "Prediction of solar radiation flues: Case study of Tetuan city in northern Morocco," no. April (2015).

15. M. Khalilian, "Experimental and numerical investigations of the thermal behavior of small solar ponds with wall shading effect," Sol. Energy, vol. 159, no. January 2017, pp. 55-65, (2018), doi: 10.1016/j.solener.2017.10.065.

16. S. G. Chakrabarty, U. S. Wankhede, R. S. Shelke, and T. B. Gohil, "Investigation of temperature development in salinity gradient solar pond using a transient model of heat transfer," Sol. Energy, vol. 202, no. September (2019), pp. 32-44, 2020, doi: 10.1016/j.solener.2020.03.052. 